\title{
Application of Water Quality Model QUAL2K to Model the Dispersion of Pollutants in River Ndarugu, Kenya
}

\author{
Letensie Tseggai Hadgu ${ }^{*}$, Maurice Omondi Nyadawa², John Kimani Mwangi1, \\ Purity Muthoni Kibetu1, Beraki Bahre Mehari1 \\ ${ }^{1}$ Department of Civil, Construction, and Environmental Engineering, Jomo Kenyatta University of Agriculture \\ and Technology, Nairobi, Kenya \\ 2Jaramogi Oginga Odinga University of Science and Technology, Bondo, Kenya \\ Email: "letensiets@yahoo.com
}

Received 1 July 2014; revised 13 August 2014; accepted 10 September 2014

Copyright @ 2014 by authors and Scientific Research Publishing Inc.

This work is licensed under the Creative Commons Attribution International License (CC BY). http://creativecommons.org/licenses/by/4.0/

(c) (i) Open Access

\section{Abstract}

Ndarugu River, Kenya, during its course through the different agricultural and industrial areas of Gatundu, Gachororo and Juja farms, receives untreated industrial, domestic and agricultural waste of point source discharges from coffee and tea factories. During wet season the water is also polluted by non-point (diffuse) sources created by runoff carrying soil, fertilizer and pesticide residues from the catchment area. This study involved the calibration of water quality model QUAL2K to predict the water quality of this segment of the river. The model was calibrated and validated for flow discharge $(Q)$, temperature $\left(\mathrm{T}^{\circ}\right)$, flow velocity $(\mathrm{V})$, biochemical oxygen demand $\left(\mathrm{BOD}_{5}\right)$, dissolved oxygen (DO) and nitrate $\left(\mathrm{NO}_{3}-\mathrm{N}\right)$, using data collected and analyzed during field and laboratory measurements done in July and November-December 2013. The model was then used in simulation and its performance was evaluated using statistical criteria based on correlation coefficient $\left(R^{2}\right)$ and standard errors (SE) between the observed and simulated data. The model reflected the field data quite well with minor exceptions. In spite of these minor differences between the measured and simulated data set at some points, the calibration and validation results are acceptable especially for developing countries where the financial resources for frequent monitoring works and higher accuracy data analysis are very limited. The water is being polluted by the human activities in the catchment. There is need for proper control of wastewater by various techniques, and preliminary treatment of waste discharges prior to effluent disposal. Management of the watershed is necessary so as to protect the river from the adverse impacts of agricultural activities and save it from further deterioration.

${ }^{*}$ Corresponding author.

How to cite this paper: Hadgu, L.T., et al. (2014) Application of Water Quality Model QUAL2K to Model the Dispersion of Pollutants in River Ndarugu, Kenya. Computational Water, Energy, and Environmental Engineering, 3, $162-169$.

http://dx.doi.org/10.4236/cweee.2014.34017 


\section{Keywords}

\section{BOD $_{5}$, DO, QUAL2K, River Pollution, Water Quality Modeling}

\section{Introduction}

Intensive developments of industry, agricultural production and ever intensive urbanization have led to the increase in number of pollutants and the amount of wastewater which pollute water flows. On the contrary, the need for water of satisfying quality continuously grows. A big amount of agricultural, municipal and industrial wastewater discharges to water bodies around the world. The discharging of degradable wastewater in water bodies result in decrease in water quality generally and particularly DO (Dissolved Oxygen) concentrations [1]. Disposal of municipal, agricultural and industrial wastewater into the rivers with little or no treatment prior to discharge is a common practice in many developing countries. This has caused a serious concern over the deterioration of river water quality. Many big and small rivers in Kenya such as Nairobi River, Athi River and their tributaries are under threat due to influx of pollutants without prior treatment. Therefore, it is important and timely that a rigorous approach to the water quality modeling of such water-courses be undertaken. Ndarugu River is a tributary of Athi River which is the second longest river in Kenya. During its flow through the different agricultural and industrial areas of Gatundu, Gachororo and Juja farms, it receives untreated industrial and agricultural waste discharges such as effluent from coffee and tea factories in the catchment area and the neighboring small settlements situated on the bank of the river. This river is a main source of fresh water for domestic use to the villages along the river bank and Nairobi City. Considering the implications of water pollution on human and aquatic health, the effective management of this segment of the river is important. QUAL2E model, developed by United States Environmental Protection Agency (USEPA), is the most widely used mathematical model for conventional pollutant impact evaluation [2]. However, several limitations of the QUAL2E have been reported. One of the major inadequacies is the lack of provision for conversion of algal death to carbonaceous biochemical oxygen demand (CBOD). Another limitation of this model is that the river section has to be segmented in to equal lengths reaches and equal the number of elements in each reach. Park and Lee [3] developed QUAL2K after modification of QUAL2E. The modifications include the expansion of computational structures and addition of more parameters. An enhanced and modernized version of QUAL2E, QUAL2K version 2.11, was developed as a continuation of modification and simplification of the model [4]. In most of the studies carried out in the application of QUAL2K model, it was observed that the model represented the field data quite well and this reasonable modeling guarantees the use of QUAL2K for future river water quality options [5]. For example Q2K was applied for water quality modeling in the Baghmati River and this application showed that, the model represented the field data pretty accurate. In this study, various water quality management options are taken into account to control DO, such as pollution loads modification and local oxygenation (by affixing weirs). Apparently local oxygenation is effective in raising DO levels [6]. The water environmental capacity of the Hongqi River (China) was simulated by Q2K. In this study Q2K was calibrated and confirmed using data from field monitoring carried out during the winter of 2009 and spring of 2010. The simulated results correlated with the measured data precisely [7]. The aim of the study was to model the water quality of the polluted segment of Ndarugu River by the comprehensive application of water quality model QUAL2K and evaluate the performance of the model using statistics based on correlation coefficient $\left(\mathrm{R}^{2}\right)$ and standard error (SE).

\section{Materials and Methods}

\subsection{Study Area and Sampling Sites}

Ndarugu River is one of the tributaries of Athi River. Ndarugu sub-catchment extends from Kieni and Kinale forest eastwards and parts of ridges of Aberdares to Juja farm all the way to Munyu where it is joined by River Komu before it joins Athi River. Ndarugu River is a perennial river with its source in the Kikuyu escarpments. It flows in south east direction and meanders through farmed slopes of Gatundu and Thika District before joining Athi River at Munyu near Kilimambogo. The tributaries of Ndarugu River are Ruabora, Githobokoni and Karakuta rivers. The study area has a catchment area of $135 \mathrm{~km}^{2}$ bounded between latitudes $1^{\circ} 00$ '36" South and 
$1^{\circ} 08^{\prime} 59^{\prime \prime}$ South and longitudes $36^{\circ} 53^{\prime} 33^{\prime \prime}$ East and $37^{\circ} 10^{\prime} 25^{\prime \prime}$ East. Its UTM zone is 37S, at an average altitude of 1560 meters above sea level. The drainage area is coded by the Government of Kenya as 3CB sub catchments in Athi Basin. The study area covers a $15.5 \mathrm{~km}$ stretch of the river starting $2.4 \mathrm{~km}$ downstream of Munya estate and $0.5 \mathrm{~km}$ downstream of Karakuta estate (upstream boundary of the stretch) to the upstream side of Juja farm (downstream boundary of the stretch). Figure 1 shows the location of catchment area in Kiambu County and Figure 2 shows the sampling sites for water quality testing along the river stretch selected for the study.

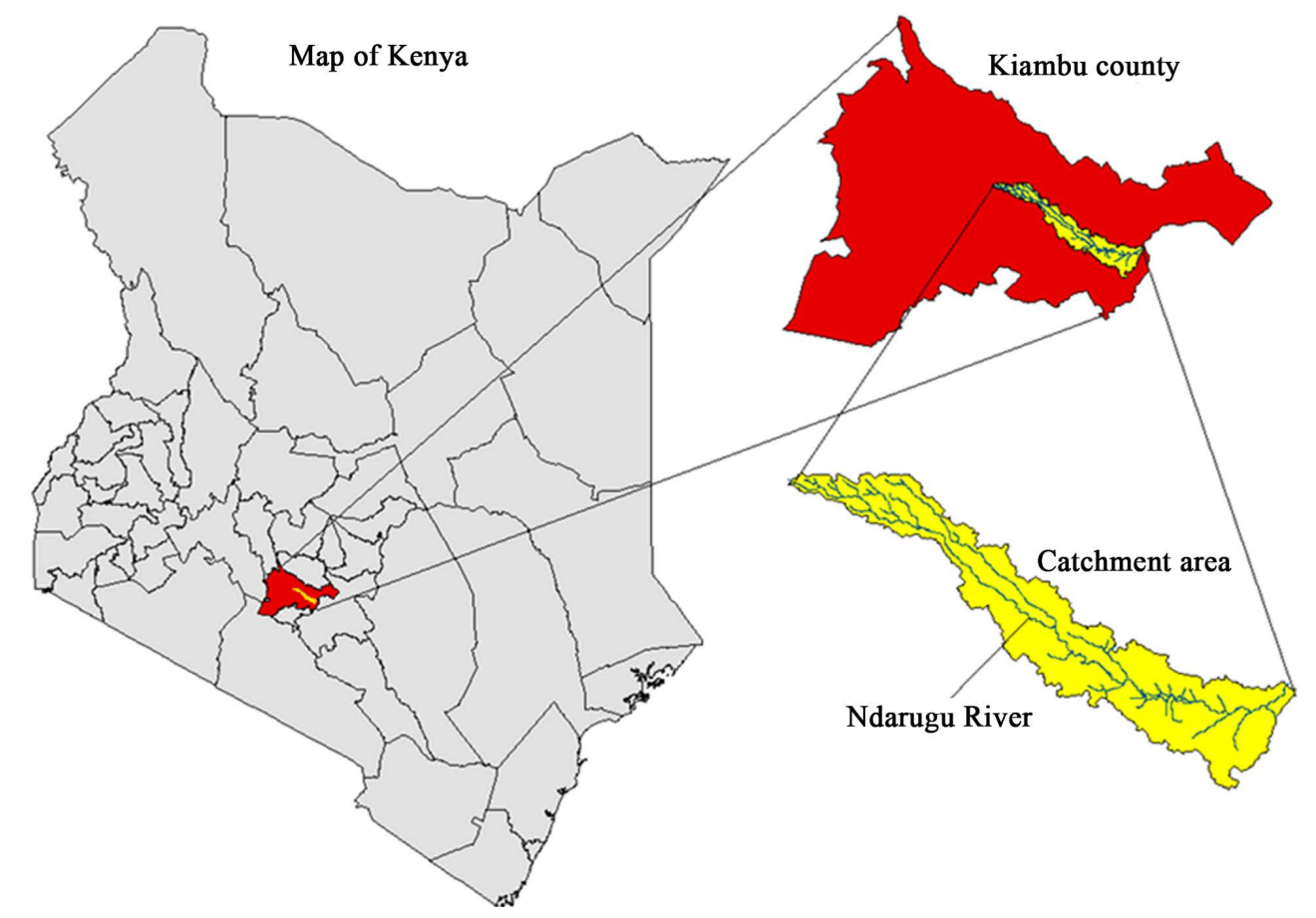

Figure 1. Location map of the study area.

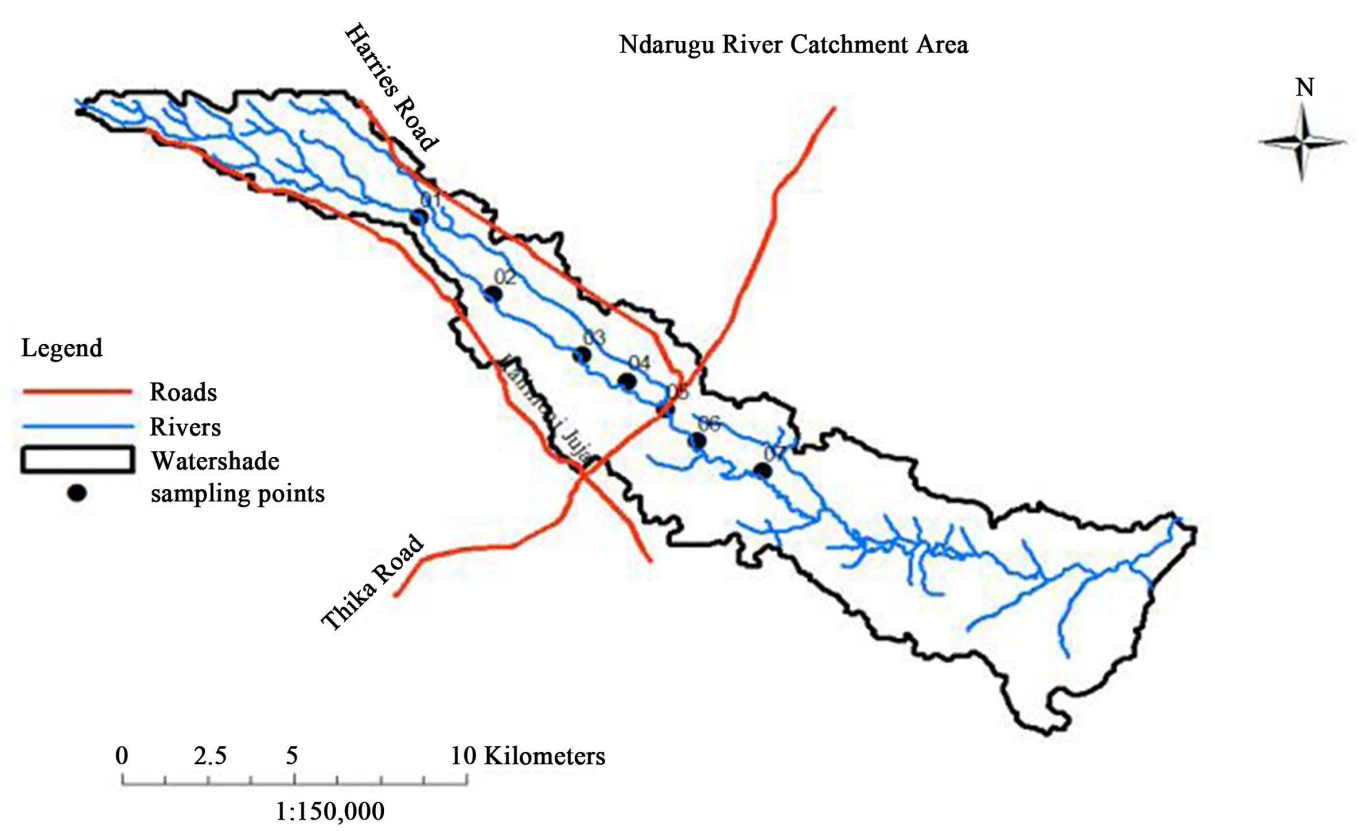

Figure 2. Catchment area and sampling sites. 


\subsection{Water Sampling and Analysis}

Water quality data of the river and wastewater of some coffee estates were collected in July 2013 for calibration during dry season and in November and December 2013 for validation during the short rainy season. Water samples were collected at $15 \mathrm{~cm}$ depth (to avoid floating material) from seven points along the river. Sampling bottles made of plastic each $500 \mathrm{ml}$ volume and Global Positioning System (GPS) were used to collect the water samples and determine the locations of sampling points. A sampling pole was used to get samples from the running water in the main body of the river since it gives the best overall sample unlike the water at the edges or that held in pools, which is likely to have a variation from the running water. The bottles were rinsed few times from the river water before taking the samples and touching the rim was avoided to prevent from any contamination of the samples. The bottle was placed inverted in the body of water 10 to $20 \mathrm{~cm}$ below the surface and then turned horizontal facing in to the flow of water. The samples analysis for eight parameters namely $\mathrm{pH}$, temperature, conductivity, turbidity, DO, BOD, nitrates and phosphates were done in situ and at Jomo Kenyatta Environmental Laboratory. Sampling was done for ten days in each season and average values of the results were presented in Table 1. These values were used in the calibration and validation of the model. In addition weather data from Meteorology Department and stream flow and velocity data from Water Resources Management Authority (WRMA) were used as input values. The river section (area of study) was divided in to six segments based on the presence of point and non-point source pollutions and the uniformity in the river characteristics such as dimensions and slopes.

\subsection{Description of the Model}

QUAL2K (Version 2.11) is a modeling framework for simulating river and stream water quality developed by Chapra et al. [4]. It is implemented within the Microsoft Windows environment. Numerical computations were programmed in Fortran 90. Microsoft Office Excel is used as the graphical user interface. All interface operations are programmed in the Microsoft Office macro language: Visual Basic for Applications (VBA). It divides the system into reaches and elements. In contrast to QUAL2E, the element size for QUAL2K can vary from reach to reach and reach lengths can vary. In addition, multiple loadings and withdrawals can be input to any element. QUAL2K model is suitable for simulating the hydrological and water quality conditions of a small river. It is a simple one-dimensional model that simulates basic stream transport and mixing processes. It allows specifying many of the kinetic parameters on a reach-specific basis. A complete discussion of the model theory is described in QUAL2K Documentation and User's Manual [4]. Therefore, QUAL2K was selected as the tool to develop the Ndarugu River water quality model.

Table 1. Physicochemical parameters of the water samples in dry and wet seasons.

\begin{tabular}{ccccccccc}
\hline $\begin{array}{c}\text { Sampling } \\
\text { Points }\end{array}$ & Season & $\mathrm{pH}$ & Temp. $\left({ }^{\circ} \mathrm{C}\right)$ & $\mathrm{EC}(\mu \mathrm{S} / \mathrm{cm})$ & $\begin{array}{c}\text { Turbidity } \\
(\mathrm{NTU})\end{array}$ & $\mathrm{DO}(\mathrm{mg} / \mathrm{l})$ & $\mathrm{BOD}_{5}(\mathrm{mg} / \mathrm{l})$ & $\mathrm{NO}_{3}(\mathrm{mg} / \mathrm{l})$ \\
\hline 01 & Dry & 7.18 & 18.42 & 61.5 & 25.37 & 5.79 & 19.15 & 18.6 \\
& Wet & 7.22 & 17.9 & 52.7 & 49.02 & 7.64 & 16.9 & 25.3 \\
02 & Dry & 7.1 & 18.24 & 58.6 & 25.11 & 5.57 & 19.19 & 20.4 \\
& Wet & 7.28 & 18.02 & 56.5 & 51.45 & 7.12 & 17.32 & 27.7 \\
03 & Dry & 7.09 & 18.45 & 63.7 & 24.85 & 5.17 & 19.45 & 19.3 \\
& Wet & 7.13 & 17.8 & 61.1 & 58.36 & 6.4 & 17.45 & 26.1 \\
04 & Dry & 7.06 & 18.4 & 66.9 & 25.53 & 4.82 & 19.78 & 17.6 \\
& Wet & 7.15 & 18.1 & 58.3 & 52.27 & 6.45 & 18.08 & 28 \\
05 & Dry & 7.2 & 18.44 & 66.1 & 22.09 & 4.14 & 19.84 & 19.2 \\
& Wet & 7.04 & 18.54 & 56.9 & 63.45 & 6.14 & 17.67 & 28.2 \\
06 & Dry & 6.93 & 18.37 & 67.7 & 28.21 & 4.21 & 20.24 & 18.1 \\
& Wet & 7.06 & 18.6 & 62.7 & 57.9 & 6.12 & 19.32 & 28.5 \\
\multirow{2}{*}{07} & Dry & 6.98 & 18.24 & 72.1 & 27.23 & 3.82 & 20.99 & 22.2 \\
& Wet & 6.93 & 17.1 & 64.3 & 58.6 & 5.93 & 18.99 & 28.9 \\
\hline \multirow{2}{*}{ WHO } & & $6.5-8.5$ & - & $500-5000$ & 5 & $>5$ & - & 50 \\
\hline
\end{tabular}




\subsection{Implementation of the Model}

The QUAL2K model has greater flexibility, which can follow the specific circumstances of users to set the parameter values and transform the simulation equation, satisfying user requirements for water quality simulation. The water quality data analyzed for dry season were applied for calibration. The calculation time step was set in such a way that ensures the model was maintained in the steady-state. The model was run (for validation) with another set of data (wet season) which was done without altering the calibrated parameters. This way the ability of the calibrated model to forecast the component concentration under different circumstances could be examined.

\section{Results and Discussion}

The calibration and validation results of Ndarugu River are presented in Figure 3 and Figure 4. The physicochemical parameters of the water sample used for calibration and validation of the model are shown in Table 1. These results also show the variation of the pollution levels as we move downstream along the river. Phosphates were below the detectable limits in all sampling points for the entire study period. Temperature and $\mathrm{pH}$ values did not show much variation between the dry and wet seasons. Turbidity was higher in wet season than in dry

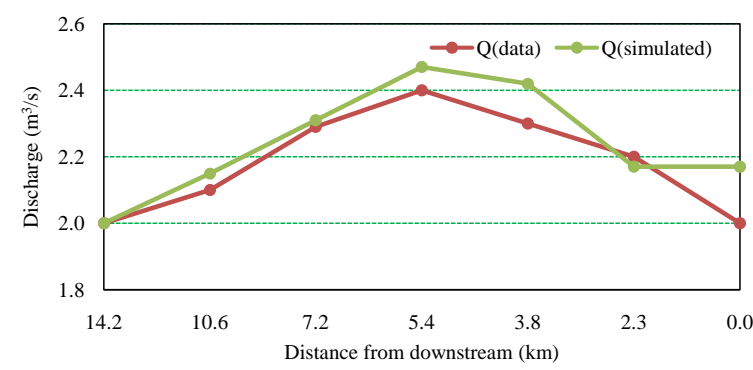

(a)

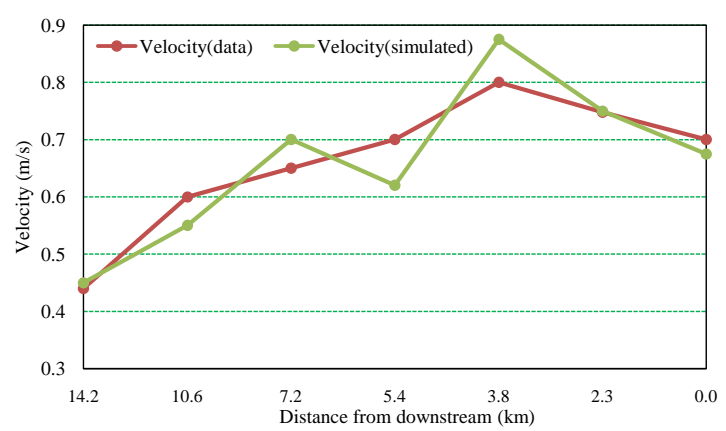

(c)

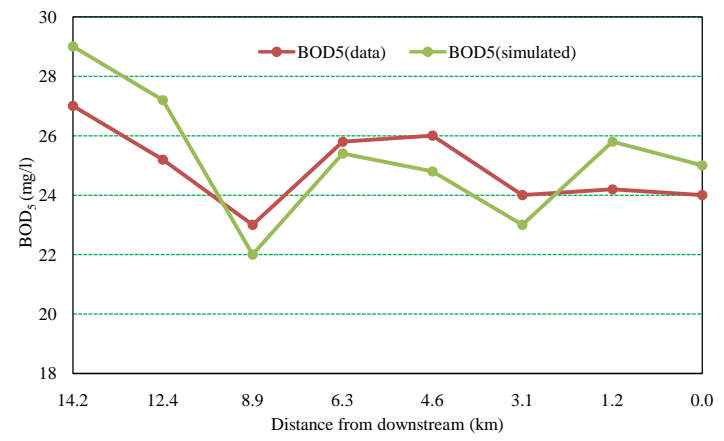

(e)

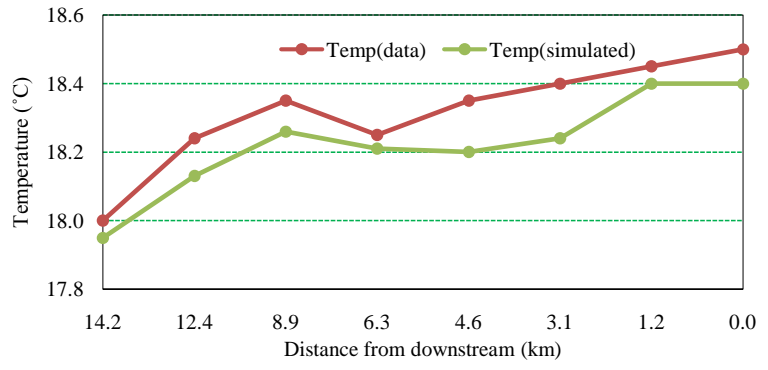

(b)

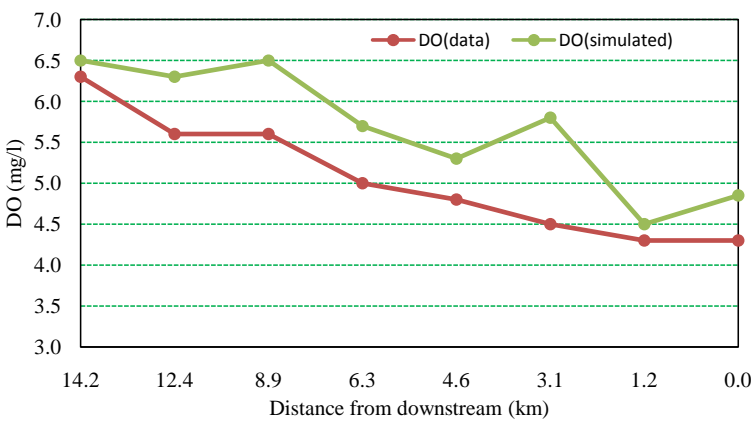

(d)

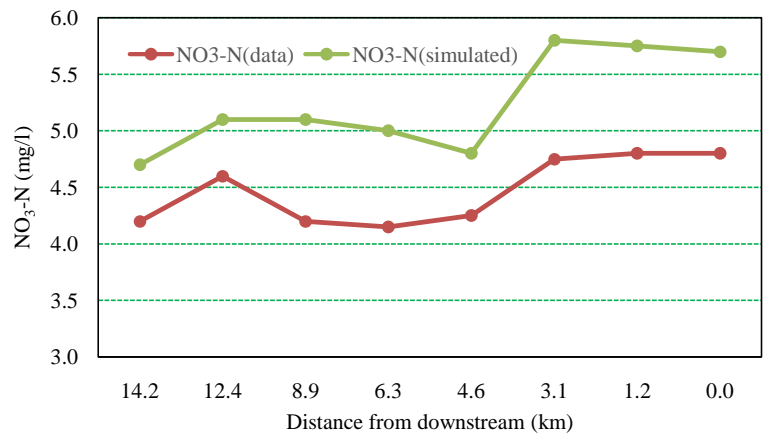

(f)

Figure 3. (a)-(f) Calibration results. (a) Calibration graph of discharge; (b) Calibration graph of temperature; (c) Calibration graph of velocity; (d) Calibration graph of DO; (e) Calibration graph of $\mathrm{BOD}_{5}$; (f) Calibration graph of $\mathrm{NO}_{3}-\mathrm{N}$. 


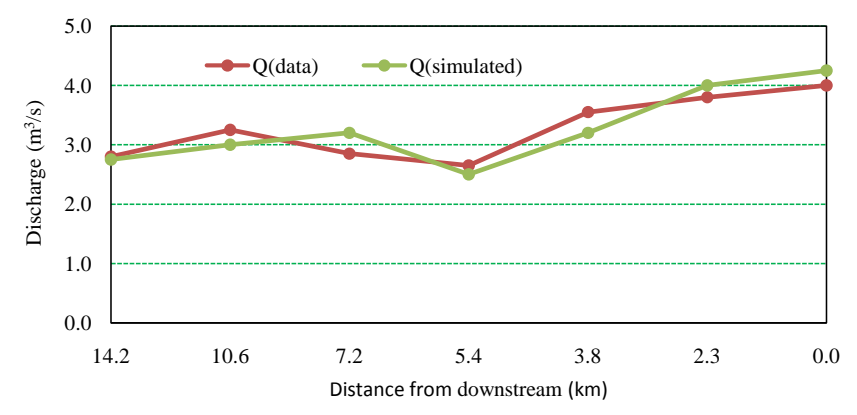

(a)

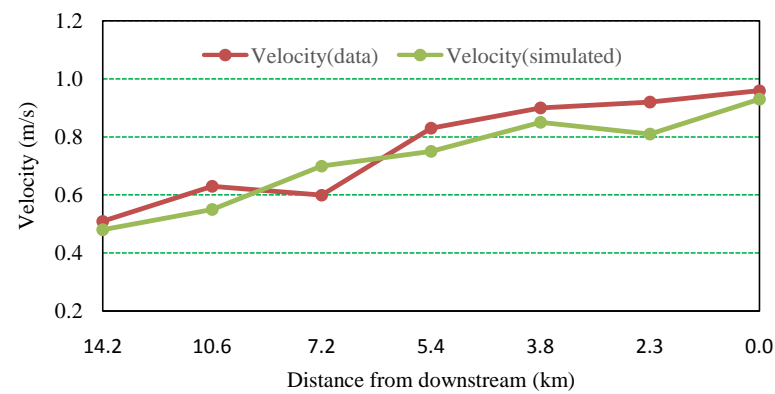

(c)

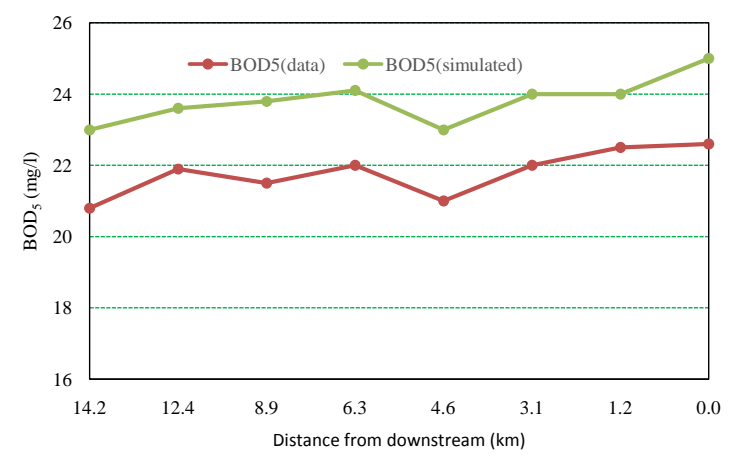

(e)

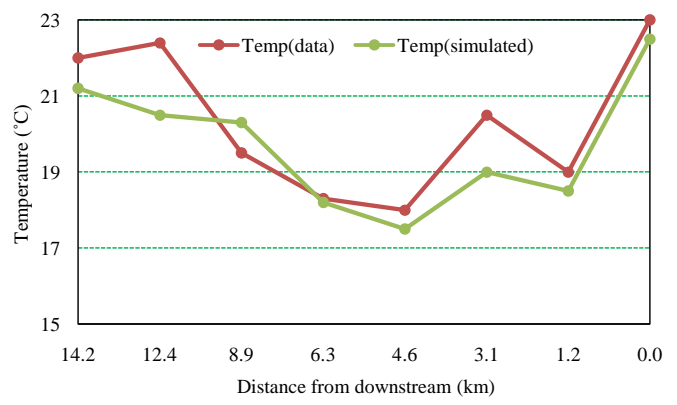

(b)

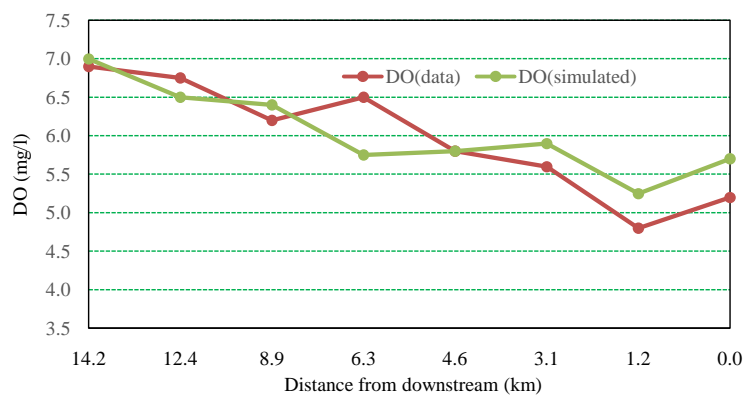

(d)

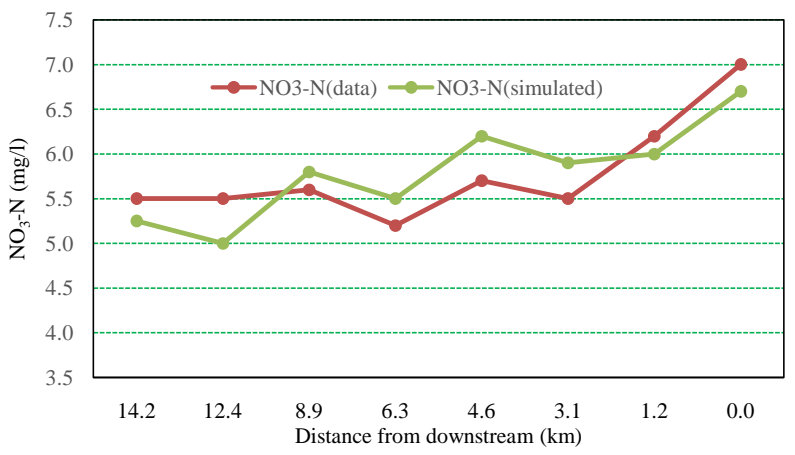

(f)

Figure 4. (a)-(f) Validation results. (a) Validation graph of discharge; (b) Validation graph of temperature; (c) Validation graph of velocity; (d) Validation graph of DO; (e) Validation graph of $\mathrm{BOD}_{5}$; (f) Validation graph of $\mathrm{NO}_{3}-\mathrm{N}$.

season. This was due to the runoff of soil and other particles from the catchment area. Electrical conductivity, an indirect measure of the total dissolved solids (TDS), was slightly lower in wet season than in dry season. This could be due to the dilution of the salt particles (TDS) by the input of rainfall and runoff. Nutrients, particularly nitrate values showed a considerable increment in wet season due to the runoff of fertilizers from the agricultural areas in the catchment. The flow and velocity patterns were varying significantly because of the low flow in the dry season and the input of runoff in the rainy season and discharge of effluents from drains across the reach. The QUAL2K generated results are in the form of graphs combined with the observed data set as shown in Figures 3(a)-(f) and Figures 4(a)-(f). The correlation between simulated and observed values for all the parameters showed a high correlation coefficient $\left(\mathrm{R}^{2}\right)$ and lower standard errors as shown in Table 2. These high correlation coefficients between observed and simulated values show that this model is perfectly reliable in modeling streams when detailed and complex data are not available due to an acceptable match of the simulated data with measured data. Thus the QUAL2K model can be used to predict the effect of point and non-point diffusion and abstraction at any section of the river on its water quality on the downstream side. This saves time and capital which would otherwise be required for frequent monitoring works. The method applied in this study can provide a basis for water environmental management in decision making for the future.

The results indicated that most of the physico-chemical water quality parameters for Ndarugu River were 
Table 2. Correlation between observed and simulated values.

\begin{tabular}{ccccc}
\hline \multirow{2}{*}{ Parameter } & \multicolumn{2}{c}{ Calibration } & \multicolumn{2}{c}{ Validation } \\
\cline { 2 - 5 } & $\mathrm{R}^{2}$ & $\mathrm{SE}$ & $\mathrm{R}^{2}$ & $\mathrm{SE}$ \\
\hline Discharge & 0.904 & 0.077 & 0.923 & 0.277 \\
Temperature & 0.956 & 0.047 & 0.907 & 0.759 \\
Velocity & 0.925 & 0.059 & 0.916 & 0.071 \\
DO & 0.882 & 0.382 & 0.855 & 0.318 \\
BOD & 0.812 & 1.394 & 0.864 & 0.354 \\
$\mathrm{NO}_{3}-\mathrm{N}$ & 0.902 & 0.491 & 0.805 & 0.538 \\
\hline
\end{tabular}

within the WHO and Kenya Bureau of Standards (KEBS) limits for drinking water and the water is therefore suitable for domestic purposes. The $\mathrm{pH}$ of the river was within the range of 6.5 to 8.5 both in the dry and rainy seasons. The DO in dry season was significantly depleted and reduced due to the mixing of these wastewaters even though re-aeration (replenishing with dilution and surface re-aeration) is expected at the surface of the river. Turbidity level varied from wet to dry season with higher levels in the wet season and was higher than the WHO and KEBS limits for drinking water throughout the study period. Electrical conductivity level reduced slightly during wet season due to the dilution from the runoff. Nutrient levels were generally low during the study period although they were higher during the wet season than the dry season. However, despite these low levels care should be taken in the application of inorganic fertilizers in order to protect the river from eutrophication.

\section{Conclusion and Recommendations}

Observed values of physical-chemical parameters of water samples showed that the river is being polluted by the human activities in the catchment. Values of discharge (Q), flow velocity (V), $\mathrm{NO}_{3}-\mathrm{N}$, electrical conductivity, $\mathrm{BOD}_{5}$ and of dissolved oxygen (DO), acquired by calibrating the water quality model, QUAL2K, are similar to observed values of physical-chemical analysis of water samples. Therefore, the water quality model QUAL2K is calibrated successfully. The performance of this model was evaluated using statistics based on correlation coefficient $\left(\mathrm{R}^{2}\right)$. The results of the evaluation revealed that there is not much variation in these values between calibration and validation. The model reflected the field data quite well with some minor exceptions. In spite of these minor differences between the measured and simulated data sets at some points, the calibration and validation results are acceptable especially for developing countries where the financial resources for frequent monitoring works and higher accuracy data analysis are very limited. There is also a need for proper control of wastewater by various techniques, and preliminary treatment of waste discharges prior to effluent disposal. Management of the watershed is necessary so as to protect the river from the adverse impacts of agricultural activities and save it from further deterioration.

\section{References}

[1] Nakhaei, N. and Shahidi, A.E. (2010) Waste Water Discharge Impact Modeling with QUAL2K, Case Study: The Zayandeh-Rood River. International Environmental Modelling and Software Society (IEMSS), Ottawa.

[2] Brown, L.C. and Barnwell, T.O. (1987) The Enhanced Stream Water Quality Models QUAL2E and QUAL2E-UNCAS (EPA/600/3-87-007). US Environmental Protection Agency, Athens.

[3] Park, S.S. and Lee, Y.S. (2002) A Water Quality Modeling Study of the Nakdong River Korea. Ecological Modeling, 152, 65-75. http://dx.doi.org/10.1016/S0304-3800(01)00489-6

[4] Chapra, S.C., Pelletier, G.J. and Tao, H. (2008) QUAL2K: A Modeling Framework for Simulating River and Stream Water Quality, Version 2.11. USA: Documentation and User’s Manual. Civil and Environmental Engineering Department, Tufts University, Medford.

[5] Kalburgi, P.B., Shivayogimath, C.B. and Purandara, B.K. (2010) Application of QUAL2K for Water Quality Modeling of River Ghataprabha (India). Journal of Environmental Science and Engineering, 4, 6-11.

[6] Kanne, P.R., Lee, S., Lee, Y.S., Kanel, S.R. and Pelletier, G.J. (2007) Application of Automated QUAL2Kw for Water 
Quality Modeling and Management in the Bagmati River. Elsevier, Amsterdam, 503-517. http://www.sciencedirect.com/

[7] Zhang, R.B., Qian, X., Yuan, X.C., Ye, R., Xia, B.S. and Wang, Y.L. (2012) Simulation of Water Environmental Capacity and Pollution Load Reduction Using QUAL2K for Water Environmental Management. International Journal of Environmental Research and Public Health, 9, 4504-4521. http://dx.doi.org/10.3390/ijerph9124504 
Scientific Research Publishing (SCIRP) is one of the largest Open Access journal publishers. It is currently publishing more than 200 open access, online, peer-reviewed journals covering a wide range of academic disciplines. SCIRP serves the worldwide academic communities and contributes to the progress and application of science with its publication.

Other selected journals from SCIRP are listed as below. Submit your manuscript to us via either submit@scirp.org or Online Submission Portal.
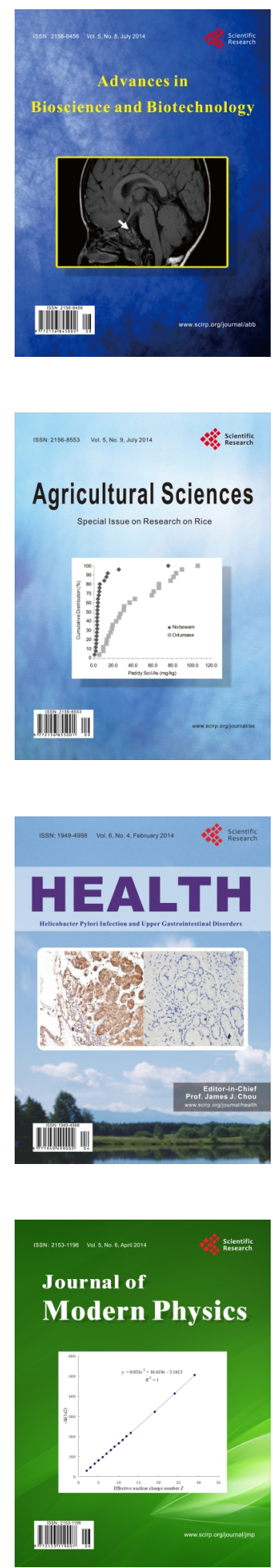
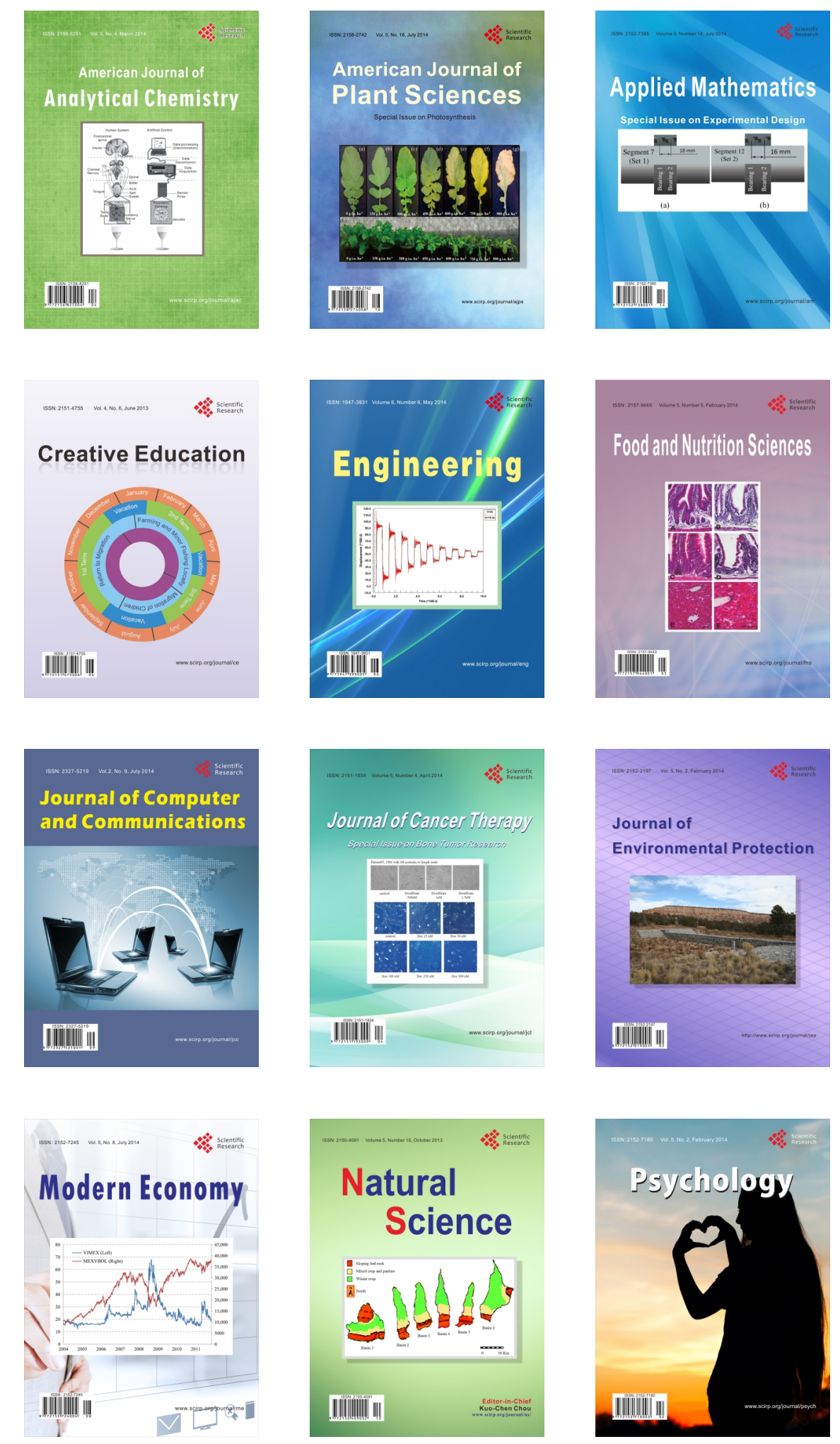